\title{
LAPAROSCOPIC URETEROLITHOTOMY VERSUS LASER LITHOTRIPSY IN MANAGEMENT OF UPPER URETERIC STONES
}

\author{
Hany Mostafa Abdallah, Karim Omar ElSaeed, Ahmed Mohamed Tawfeek and
}

Dr. Mostafa Ali Ahmed*

\begin{abstract}
:
Urology Department, Faculty of Medicine, Ain Shams University, Cairo, Egypt .Corresponding :

Mostafa Ali Ahmed

Mobile: 01002972203

E mail:

mostafa_urology@yahoo.com

Received: 29/5/2019

Accepted: 21/6/2019

Background: The optimal treatment for ureteral calculi must consider many factors, including stone composition, location and size, patient characteristics, technical skills of the surgeon, and instrument availability.

Aim of the Work: To assess the result of ureteroscopic lithotripsy using holmium laser with laproscopic ureterolithotomy in the management of proximal ureteral stones larger than $10 \mathrm{~mm}$.

Patients and Methods: 80 patients with unilateral upper ureteral stones were randomly divided into two groups: one group underwent ureteroscopic holmium laser lithotripsy $(n=40)$, and another group underwent laparoscopic ureterolithotomy $(n=40)$. Operating time, postoperative hospitalization time, stone clearance rate and perioperative complications were compared.

Results: Operation was successfully performed in all 80 cases, and no open surgery was converted in any case. In the ureteroscopy and laparoscopy groups, the mean operating time was $33.83 \pm 6.39$ min and $107.25 \pm 20.13 \mathrm{~min}$, respectively, their hospitalization time was $1.65 \pm 0.48$ days vs. $3.90 \pm 0.63$ days, and stone clearance rate was $880.0 \%$ (32/40) vs. 95\% (38/40), and residual stones were removed by extracorporeal shock-wave lithotripsy (ESWL). All patients were followed up for more than three months, and no serious complications such as ureterostenosis occurred.

Conclusion: Laparoscopic ureterolithotomy and Ureteroscopy are both effective and reliable for the treatment of proximal ureteral stones. However, considering the shorter operation and hospitalization times we suggest that ureteroscopy, as a minimally invasive method, may be the first choice in the treatment of proximal ureteral stones.
\end{abstract}

Keywords: Laparoscopic Ureterolithotomy, Ureteroscopy Management, Lithotripsy, Ureteral Stone.

\section{INTRODUCTION:}

The optimal treatment for ureteral calculi must consider many factors, including stone composition, location and size, patient characteristics, technical skills of the surgeon, and instrument availability. ${ }^{1}$

Ureteroscopy has already become amajor technique for the diagnosis and treatment of ureteric lesions. For upper urinary tract lithiasis, the use of ureteroscopic approach has been increasing continuously ${ }^{1}$.

The development of smaller-caliber semirigid and flexible ureteroscopes and the introduction of improved instrumentation, including deflectable-tip endoscopes, ureteral access sheaths, superior optics, and 
stone-retrieval devices, have led to the development of ureteroscopy as a safe and effective treatment option for ureteral stones in all locations. ${ }^{2}$

Meanwhile, laparoscopy as a minimally invasive treatment is gradually gaining place in the treatment of urinary stones. ${ }^{3}$

The highest level of evidence was IIa for laparoscopic ureterolithotomy and recommended (grade B) for large impacted ureteral stones or when endoscopic ureterolithotripsy or shock wave lithotripsy (SWL) has failed. ${ }^{4}$

An impacted stone is defined as a stone that cannot be bypassed either by a wire, or a catheter, or a stone remaining at the same site in the ureter for over 2 months. ${ }^{5}$

Ureteroscopic lithotripsy (URSL) using holmium laser has good results with low complications, while stone migration or complications still existed. ${ }^{6}$

\section{AIM OF THE WORK:}

To assess the result of ureteroscopic lithotripsy using holmium laser with laproscopic ureterolithotomy in the management of proximal ureteral stones larger than $10 \mathrm{~mm}$.

\section{PATIENTS AND METHODS:}

This study was conducted on 80 patients with upper ureteric stone over a period of 2 years from January 2017 to January 2019. The study protocol was approved by the Urology Department of Ain Shams University review board and Faculty of Medicine Ain Shams University Research Ethics Committee (FMASU REC). Informed consents were obtained from all participants.

Patients were allocated into two groups (A) and (B);
- Group (A) includes 40 patients managed by laser lithotripsy either by flexible ureteroscopy, rigid ureteroscopy.

- Group (B) includes 40 patients managed by laparoscopic ureterolithotomy.

\section{Preoperative Evaluation:}

All patients underwent detailed history taking about medical, sexual, family and surgical history. Demographic features and medical history included age, occupation, body mass index (BMI), parity, and past history of previous stone surgeries.

All patients underwent a complete blood count, serum urea and creatinine measurement, bleeding and coagulation profile analysis, urinalysis and urine culture, $\mathrm{KUB}$, intravenous urography, and computed tomography without contrast.

\section{Surgical technique:}

\section{Anesthesia:}

General or spinal anesthesia in case of ureteroscope.

\section{Position:}

Lithotomy position in case of ureteroscopy for laser lithotripsy.

\section{Ureteroscope Procedure:}

In this procedure, 7.5- or 8.5-F semirigid ureterooscopy (R. Wolf TM) was used for URS and flexible URS (Karl Storz Flex$\mathrm{X}$ 2TM) was used secondarily when necessary. ${ }^{7}$

\section{Laproscopic ureterolithotomy:}

Three trocars (10-12 $\mathrm{mm})$ were used for laparoscopic ureterolithotomy. The initial port was placed by the open method at the junction of the 12th rib and posterior axillary line. In the open method, a $1.5 \mathrm{~cm}$ incision was made in the fascia of the external oblique muscle.

The retroperitoneal space was accessed by puncturing the fascia of the transversus abdominis muscle with a blunt clamp. First, 
an $800-\mathrm{mL}$ space was created with a finger and then with a balloon dissector while the peritoneum was shifted medially at the same time.

The second port was placed $1 \mathrm{~cm}$ anterior to the 11 th rib. The third port was placed at the anterior axillary line, $2 \mathrm{~cm}$ superior and $2 \mathrm{~cm}$ medial to the spina iliaca anterior superior.

After expansion of the retroperitoneum and opening of Gerota's fascia, the ureter was identified over the psoas muscle. Protuberance of the stone was noted, and the stone was grasped with a Babcock clamp. After stabilization of the stone, the ureter was incised vertically with a wedge-tipped endoscopic scalpel.

The stone was extracted with right-angle forceps. It was placed in an endobag, and a $26 \mathrm{~cm}$ antegrade DJ ureteral catheter was inserted.

The ureteral incision was closed using 4/0 Vicryl suture. A Hemovac drainage catheter was placed in the periureteric area near the second port site. The DJ catheter was left in place for 7 days. ${ }^{8}$

\section{Postoperative care and follow up:}

The stone-free rate after the first attempt was assessed with X-ray, KUB on the first postoperative day.

The first attempt was considered successful in patients who had residual fragments smaller than $2 \mathrm{~mm}$ and no conversion of the primary procedure to another.

Stone status was assessed with physical examination, urinalysis, X-ray, KUB, and urinary ultrasound.

When there was any suspicion, noncontrast computed tomography was used to assess the stone status.

All statistical analyses were performed with SPSS version 20.0 statistical software. Means were compared with group $t$ test, and rates were compared with Chi-square test.

$\mathrm{P}<0.05$ was considered statistically significant.

\section{RESULTS}

80 patients were included in this study, there was no significant statistical difference among the studied groups regarding age, sex, BMI and stone site, which means that patients were homogenously distributed between both groups as shown in table (1).

Table (1): Demographic data of patients

\begin{tabular}{|c|c|c|c|c|c|}
\hline & Group I & Group II & \multirow[t]{2}{*}{ P-value } & \multirow[t]{2}{*}{ Sig. } \\
\hline & & No. $=40$ & No. $=40$ & & \\
\hline \multirow[t]{2}{*}{ Age } & Mean \pm SD & $42.12 \pm 11.91$ years & $46.80 \pm 10.99$ years & \multirow[t]{2}{*}{0.155} & \multirow[t]{2}{*}{ NS } \\
\hline & Range & $(22-65)$ & $(33-65)$ & & \\
\hline \multirow[t]{2}{*}{ Gender } & Male & $25(62.5 \%)$ & $27(67.5 \%)$ & \multirow[t]{2}{*}{0.639} & \multirow[t]{2}{*}{ NS } \\
\hline & Female & $15(37.5 \%)$ & $13(32.5 \%)$ & & \\
\hline \multirow[t]{2}{*}{ BMI } & Mean \pm SD & $27.60 \pm 3.45$ & $28.18 \pm 3.34$ & \multirow[t]{2}{*}{0.451} & \multirow[t]{2}{*}{$\mathrm{NS}$} \\
\hline & Range & $23-33$ & $23-33$ & & \\
\hline
\end{tabular}

Operative time was significantly shorter at ureteroscopy group, mean operative time was $33.83 \pm 6.39$ minutes, while at laparoscopy group the mean operative time was $107.25 \pm 20.13$ minutes, which was highly significant shorter in ureteroscopy group (p-value: 0.000 ).

At ureteroscopy group the mean duration of hospital stay was $1.65 \pm$ 0.48 days which was shorter than that in laparoscopy group the median duration was 
$3.90 \pm 0.63$ days and the difference was statistically significant (P-value: 0.000$)$.

Residual stone occurred in 8 cases $(20 \%)$ in ureteroscopy group, while in laparoscopy group occurred in 2 cases $(5 \%)$ and the difference was statistically significant. (Pvalue: 0.043 ).

At ureteroscopy group 12 patient(30\%) needed postoperative analgesic, while at laparoscopy group 28 patient $(70 \%)$ needed postoperative analgesic ( $\mathrm{p}$-value:0.000), in ureteroscopy group 5 patient(12.5\%) had ureteral false passage, while at laparoscopy group no patient $(0 \%)$ had ureteral false passage ( $\mathrm{p}$-value:0.021).

In our study; ureteral false passage was significantly more in the ureteroscopy group more than laproscopy group $(12.5 \%$ and $0 \%$, respectively), which is significant (pvalue:0.021), while Yuan Shaol et al. found in 2015 that ureteral false passage was significantly more in the ureteroscopy group more than laproscopy group $(3.6 \%$ and $0 \%$, respectively).

Urine leakage was more in laproscopic ureter lithotomy occured in 2 cases $(5 \%)$ while no cases of urine leakage occurred in ureteroscope group, while Yuan Shao et al.found that urine leakage occur in 5 cases (3.7\%) of laproscopic ureterolithotomy and no cases of urine leakage occurred in ureteroscope group.

\section{DISCUSSION:}

Ureteral stones are usually treated with SWL and URS. Various studies reported that SWL has lower stone-free rates and a higher number of procedures for large proximal and mid-ureter stones. ${ }^{91011}$

Although URS is the first option for ureteral stones, its success rate is decreased in large mid or upper-ureter stones. ${ }^{12}$

Laparoscopic surgery developed markedly in recent years, and the indications for open surgery have thus significantly decreased in patients with renal and ureteric stones, shorter convalescence period, less analgesic requirement, early mobilization and early oral feeding are advantages of laparoscopic surgery. ${ }^{13}$

In our study; the operative time was significantly shorter in ureteroscopy group using laser lithotripsy than in the laparoscopic ureterolithotomy group $33.83 \pm$ $6.39 \mathrm{~min}$ and $107.25 \pm 20.13 \mathrm{~min}$, respectively(p-value:0.000).

Basiri and his collages in their randomized controlled study on total of 100 patients found that mean operative time in ureteroscopy group was $42.7 \pm 17.9 \mathrm{~min}$, while in laparoscopic ureterolithotomy was $127.8 \pm 41.8$ min. $^{14}$

The shorter operative time with URS was reported in various studies which can reflect the regular practice and the familiarity of most urologists with this procedure. 151617

In our study; the hospital stay was significantly shorter in ureteroscopy group using laser lithotripsy than in the laproscopic ureter lithotomy group $1.65 \pm 0.48$ days and $3.9 \pm 0.63$ days, respectively (pvalue:0.000).

Liu and his colleagues found in their randomized controlled study on 90 patients that mean hospital stay in ureteroscopy group was $5.1 \pm 0.6$ days while in laparoscopy group was $4.5 \pm 0.48$ days. ${ }^{16}$

The stone free rate was significantly more in the laparoscopy group than ureteroscopy group using laser lithotripsy $95 \%$ and $80 \%$, respectively(p-value: 0.043 ).

These results were consistent with Neto and his colleagues who compared laparoscopic ureterolithotomy and ureteroscope in 48 patients with large proximal ureteral stones $>1 \mathrm{~cm}$, The stone clearance rate was significantly higher in the laparoscopy group $(93.3 \%)$ as compared to 
the ureteroscopy group $(62.5 \%)$ and SWL $(35.7 \%)$ group. ${ }^{18}$

The postoperative analgesic demand was significantly more in the laparoscopy group than ureteroscopy group $70 \%$ and $30 \%$, respectively (p-value:0.000).

Yuan Shao and his colleagues found in there study held on total of 275 patients that postoperative analgesic demand in laproscopy group and in ureteroscopy group (59.6\% and $25.9 \%$, respectively). ${ }^{19}$

In our study; ureteral false passage was significantly more in the ureteroscopy group more than laparoscopy group (12.5\% and $0 \%$, respectively), which is significant (pvalue:0.021), while Yuan Shao et al. found in 2015 that ureteral false passage was significantly more in the ureteroscopy group more than laparoscopy group $(3.6 \%$ and $0 \%$, respectively). 19

Urine leakage was more in laproscopic ureter lithotomy occured in 2 cases $(5 \%)$ while no cases of urine leakage occurred in ureteroscope group, while Yuan Shao et al. found that urine leakage occur in 5 cases (3.7\%) of laproscopic ureterolithotomy and no cases of urine leakage occurred in ureteroscope group. ${ }^{19}$

There were no significant difference between ureteroscopy group and laproscopy group as regard postoperative temporary fever ( $25 \%$ and $10 \%$, respectively), urinary tract infection ( $12.5 \%$ and $5 \%$, respectively), urine leakage $(0 \%$ and $5 \%$, respectively), and ureteral perforation ( $5 \%$ and $0 \%$, respectively).

\section{Conclusion:}

Laparoscopic ureterolithotomy and FURS are both effective and reliable for the treatment of proximal ureteral stones. However, considering the shorter operation and hospitalization times we suggest that ureteroscopy, as a minimally invasive method, may be the first choice in the treatment of proximal ureteral stones.

\section{REFERENCES:}

1. Geavlete P, Georgescu D, Niţă G, Mirciulescu V and Cauni V (2006): Complications of 2735 retrograde semirigid ureteroscopy procedures: a single-center experience. Journal of Endourology, 20(3): 179-185.

2. Leone NT, Garcia-Roig M and Bagley DH (2010): Changing trends in the use of ureteroscopic instruments from 1996 to 2008. Journal of Endourology, 24(3): 361365.

3. Hruza M, Schulze M, Teber D, Gözen AS and Rassweiler JJ (2009): Laparoscopic techniques for removal of renal and ureteral calculi. Journal of Endourology; 23(10): 1713-1718.

4. Skolarikos A, Papatsoris AG, Albanis S and Assimos D (2010): Laparoscopic urinary stone surgery: an updated evidence-based review. Urological Research; 38(5): 337344.

5. Goel R, Aron M, Kesarwani PK, Dogra PN, Hemal AK and Gupta NP (2005): Percutaneous antegrade removal of impacted upper-ureteral calculi: still the treatment of choice in developing countries. Journal of Endourology; 19(1): 54-57.

6. De La Rosette J, Denstedt J, Geavlete P, Keeley F, Matsuda T, Pearle M, Preminger G, Traxer O and CROES URS Study Group (2014): The clinical research office of the endourological society ureteroscopy global study: indications, complications, and outcomes in 11, 885 patients. Journal of Endourology; 28(2): 131-139.

7. Karakoyunlu N, Goktug G, Şener NC, Zengin K, Nalbant I, Ozturk U, Ozok U and Imamoglu A (2015): A comparison of standard PCNL and staged retrograde FURS in pelvis stones over $2 \mathrm{~cm}$ in diameter: a prospective randomized study. Urolithiasis; 43(3): 283-287. 
8. Topaloglu H, Karakoyunlu N, Sari S, Ozok HU, Sagnak L and Ersoy H (2014): A comparison of antegrade percutaneous and laparoscopic approaches in the treatment of proximal ureteral stones. BioMed Research International; 2014.

9. Youssef RF, El-Nahas AR, El-Assmy AM, El-Tabey NA, El-Hefnawy AS, Eraky I, ElKenawy MR, El-Kappany HA and Sheir KZ (2009): Shock wave lithotripsy versus semirigid ureteroscopy for proximal ureteral calculi $(<20 \mathrm{~mm})$ : a comparative matchedpair study. Urology; 73(6): 1184-1187.

10. Wu CF, Shee JJ, Lin WY, Lin CL and Chen CS (2004): Comparison between extracorporeal shock wave lithotripsy and semirigid ureterorenoscope with holmium: YAG laser lithotripsy for treating large proximal ureteral stones. The Journal of Urology; 172(5): 1899-1902.

11. Lopes Neto AC, Korkes F, Silva JL, Amarante RDM, Mattos MHE, TobiasMachado M and Pompeo ACL (2012): Prospective randomized study of treatment of large proximal ureteral stones: extracorporeal shock wave lithotripsy versus ureterolithotripsy versus laparoscopy. The Journal of Urology; 187(1): 164-168.

12. Castro EP, Osther PJ, Jinga V, Razvi $H$, Stravodimos KG, Parikh K, Kural AR, Jean $\mathrm{J}$ and CROES Ureteroscopy Global Study Group (2014): Differences in ureteroscopic stone treatment and outcomes for distal, mid-, proximal, or multiple ureteral locations: the Clinical Research Office of the Endourological Society ureteroscopy global study. European Urology; 66(1): 102-109.

13. Kaygısız O, Coşkun B, Kılıçarslan $H$, Kordan Y, Vuruşkan H, Özmerdiven G and Yavaşcaoğlu İ (2015): Comparison of ureteroscopic laser lithotripsy with laparoscopic ureterolithotomy for large proximal and mid-ureter stones. Urologia Internationalis; 94(2): 205-209.
14. Basiri A, Simforoosh N, Ziaee A, Shayaninasab H, Moghaddam SMMH and Zare S (2008): Retrograde, antegrade, and laparoscopic approaches for the management of large, proximal ureteral stones: a randomized clinical trial. Journal of Endourology; 22(12): 2677-2680.

15. Fang YQ, Qiu JG, Wang DJ, Zhan HL and Situ J (2012): Comparative study on ureteroscopic lithotripsy and laparoscopic ureterolithotomy for treatment of unilateral upper ureteral stones. Acta Cirurgica Brasileira; 27(3): 266-270.

16. Liu Y, Zhou Z, Xia A, Dai H, Guo L and Zheng J (2013): Clinical observation of different minimally invasive surgeries for the treatment of impacted upper ureteral calculi. Pakistan Journal of Medical Sciences; 29(6): 1358.

17. Kumar A, Vasudeva P, Nanda B, Kumar N, Jha SK and Singh H (2015): A prospective randomized comparison between laparoscopic ureterolithotomy and semirigid ureteroscopy for upper ureteral stones $>2 \mathrm{~cm}$ : a single-center experience. Journal of Endourology; 29(11): 12481252.

18. Lopes Neto AC, Korkes F, Silva JL, Amarante RDM, Mattos MHE, TobiasMachado M and Pompeo ACL (2012): Prospective randomized study of treatment of large proximal ureteral stones: extracorporeal shock wave lithotripsy versus ureterolithotripsy versus laparoscopy. The Journal of Urology; 187(1): 164-168.

19. Shao $Y$, Wang DW, Lu GL and Shen ZJ (2015): Retroperitoneal laparoscopic ureterolithotomy in comparison with ureteroscopic lithotripsy in the management of impacted upper ureteral stones larger than $12 \mathrm{~mm}$. World Journal of Urology; 33(11): 1841-1845. 
مقارنة بين تفتيت الحصوات بالليزر واستخراج الحصوات عن طريق منظار البطن فى علاج حصوات اعلى الحالب

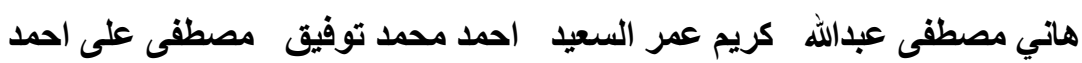

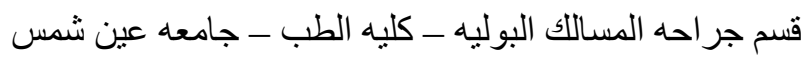

\section{المستخلص}

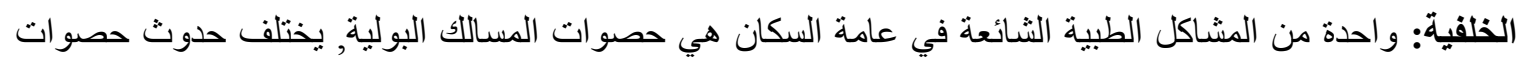

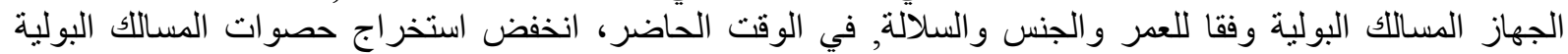
جراحيا بسبب التطور الكبير في تقنيات المناظير.

الههف من الاراسه: مقارنة بين تفتيت الحصوات بالليزر واستخر اج الحصوات عن طريق منظار البطن فى علاج

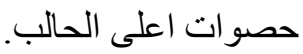

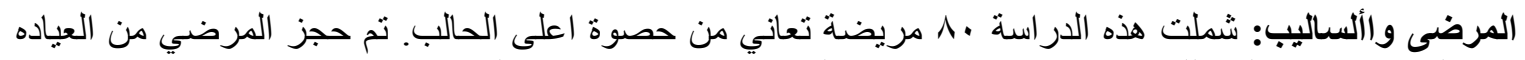

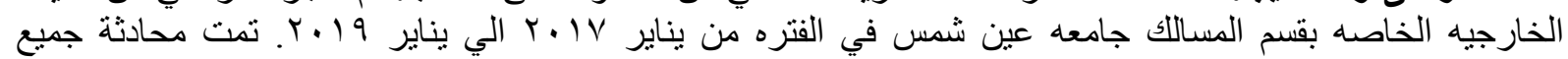

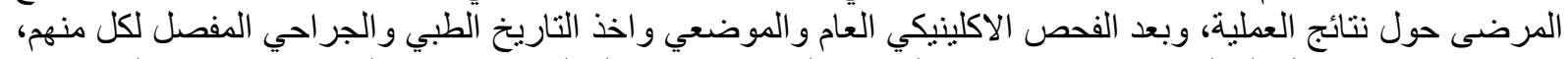

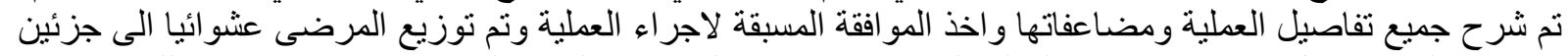

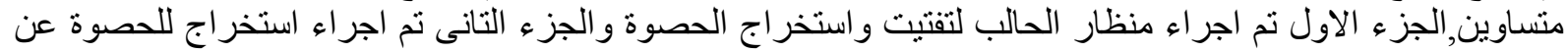

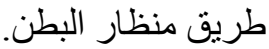

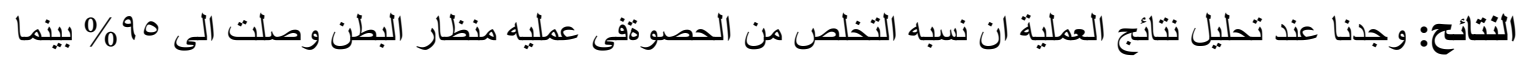

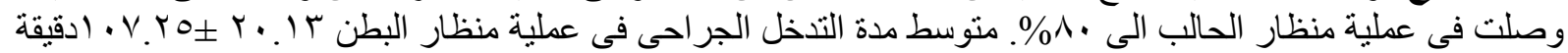

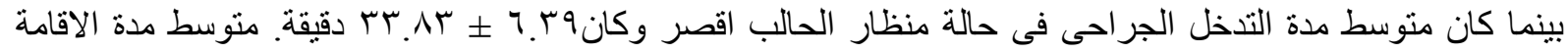

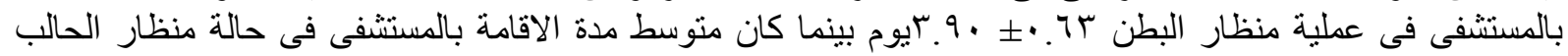

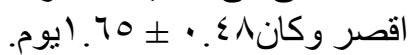

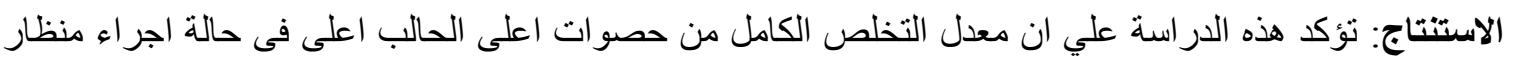

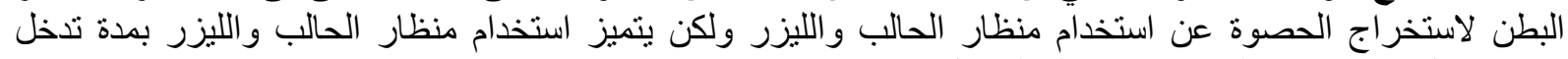
جر احى اقل ومدة اقامة بالمستشفى بعد العملية اقل. 